\title{
Penerapan Teknik Penarikan Contoh Kuota untuk Penentuan Paket Aplikasi pada Distro IPB Linux Operating System
}

\section{Implementation of a Quota Sampling Technique to Determine Application Package on IPB Linux Operating System Distribution}

\author{
ANTONI, HERU SUKOCO*
}

\begin{abstract}
Abstrak
Penerapan lisensi GNU General Public License (GPL) menyebabkan munculnya berbagai sistem operasi berbasis GNU/Linux. Hal ini dikarenakan banyak perusahaan, masyarakat umum, dan komunitas tertentu yang mengembangkan pemaketan aplikasi (distro) Linux sesuai dengan kebutuhan masing-masing. Distro IPB Linux Operating System (ILOS) 2013 merupakan sistem operasi GNU/Linux yang dikembangkan untuk menunjang kebutuhan perangkat lunak mahasiswa Institut Pertanian Bogor (IPB). ILOS 2013 dibangun menggunakan metode remastering menggunakan distro Ubuntu 12.04.2 LTS sebagai distribusi induk. Mahasiswa IPB memiliki karakteristik yang heterogen dan terdiri atas beberapa kompetensi keilmuan yang berbeda. Oleh karena itu, dalam penelitian ini dilakukan survei dengan metode penarikan contoh kuota. Survei yang dilakukan melibatkan 100 mahasiswa dari semua jurusan di IPB untuk menentukan kebutuhan perangkat lunak bagi mahasiswa IPB. Berdasarkan hasil pengolahan data survei, paket distro ILOS meliputi 38 aplikasi yang terdiri atas 5 aplikasi untuk kebutuhan sains, 7 aplikasi perkantoran, 5 aplikasi pemrograman, 3 aplikasi manajemen basisdata, 2 aplikasi jaringan, 1 aplikasi sistem informasi geografis (SIG), 5 aplikasi computer aided design (CAD) dan desain grafis, 6 aplikasi internet, 3 aplikasi multimedia dan 1 aplikasi utilitas telah dipaketkan pada distro ILOS 2013 untuk memenuhi kebutuhan mahasiswa IPB. Seluruh aplikasi dipaketkan dalam bentuk DVD Installer ILOS 2013.
\end{abstract}

Kata kunci: GNU/Linux, ILOS, penarikan contoh kuota, remastering, Ubuntu.

\section{Abstract}

GNU General Public License (GPL) implementation has triggered the emergence of various operating systems based on GNU/Linux. This is due to many companies, individuals, and communities, developing their own package of the Linux distribution to accomplish their needs. ILOS 2013 distribution is a GNU/Linux operating system developed to support the software required by the students of Bogor Agricultural University $(I P B)$. It is built by using a remastering technique from Ubuntu 12.04.2 LTS as the root distribution. Nowadays, $I P B$ students have heterogeneous characteristics and come from various scientific competences. Therefore, the research established a survey using quota-sampling technique. The study takes 100 students from all departments in IPB to determine all software package required by IPB students. The survey results 38 applications in ILOS 2013. It comprises 5 scientific, 7 office utility, 5 programming, 3 database management system, 2 computer network, 1 geographic information system (GIS), 5 computer aided design (CAD) and graphic design, 6 internet, 3 multimedia, and 1 computer utility applications to meet the needs of IPB students. The entire applications packaged in DVD Installer ILOS 2013.

Keywords: GNU/Linux, ILOS, quota sampling, remastering, Ubuntu.

\section{PENDAHULUAN}

Perangkat lunak open source berkembang pesat dewasa ini, dengan kode sumber yang tersedia dan bebas untuk dipelajari dan dikembangkan. Ketersediaan dan kebebasan tersebut membuat banyak aplikasi alternatif yang tersedia sebagai pengganti perangkat lunak komersil untuk berbagai kebutuhan dalam penggunaan komputer.

Sistem operasi berbasis GNU/Linux merupakan salah satu bentuk perangkat lunak yang dikembangkan secara open source dan didistribusikan di bawah lisensi GNU General 
Public License (GPL). Perangkat lunak yang memiliki lisensi GNU GPL memberikan izin kepada penggunanya untuk memperbanyak, memodifikasi, dan mendistribusikan kembali secara bebas. Pendistribusian sistem operasi berbasis GNU/Linux disebut sebagai distribusi (disingkat dengan istilah "distro") Linux. Setiap distro Linux memiliki keunikan paket aplikasi yang tersedia dan memiliki tujuan tertentu.

Penerapan lisensi GNU GPL menyebabkan banyaknya distro Linux yang beredar di masyarakat karena banyak perusahaan, orang, dan kelompok atau komunitas tertentu yang mengembangkan distro Linux sesuai dengan kebutuhan masing-masing. Beberapa contoh distro Linux yang populer adalah distro Linux BlankOn, yang dikembangkan oleh Yayasan Penggerak Linux Indonesia (YPLI) untuk kebutuhan komputer umum di Indonesia, distro Red Hat, yang dikembangkan oleh perusahaan Red Hat dan ditargetkan untuk kebutuhan perusahaan serta pengguna komersial, dan distro Sabily, yang dikembangkan untuk kebutuhan pengguna komputer beragama Islam.

Distro IPB Linux Operating System (ILOS) merupakan metode pemaketan tentang sistem operasi open source yang berbasis Linux. Lubis (2008) telah melakukan penelitian pertama pembuatan distro ILOS dengan metode remastering. Manunggal (2009) mengembangkan ILOS menjadi distro untuk pendidikan bagi mahasiswa dan dosen FMIPA IPB. Feri (2011) mengembangkan distro ILOS untuk kebutuhan pegawai dan dosen IPB. Selanjutnya Musthofa (2011) mengembangkan ILOSmedia, yaitu distribusi ILOS yang menyediakan paket-paket multimedia open source, dan Ardhie (2011) membangun versi ILOS untuk laboratorium Departemen Ilmu Komputer IPB. Penelitian di atas menjadi dasar penelitian ini untuk mengembangkan ILOS menjadi sebuah distro yang menunjang kebutuhan mahasiswa IPB.

Pengembangan distro ILOS untuk menunjang kebutuhan mahasiswa IPB, memerlukan sebuah metode khusus untuk penentuan perangkat lunak yang akan dipaketkan ke dalam distro ILOS yang dibangun. Mahasiswa IPB memiliki karakteristik yang heterogen dan terdiri atas berbagai kompetensi keilmuan yang berbeda. Oleh karena itu, untuk proses penentuan kebutuhan perangkat lunak mahasiswa IPB dilakukan survei dengan metode penarikan contoh kuota (quota sampling).

Penelitian ini dilakukan untuk menentukan kebutuhan aplikasi mahasiswa IPB, mendapatkan padanan aplikasi serupa yang dapat berfungsi pada sistem operasi GNU/Linux, dan membuat pemaketan distribusi ILOS 2013 sebagai sistem operasi alternatif untuk menunjang kebutuhan aplikasi mahasiswa IPB.

\section{Ruang Lingkup Penelitian}

1 Survei kebutuhan perangkat lunak untuk mahasiswa IPB dilakukan terhadap mahasiswa Pascasarjana, Sarjana, dan Diploma IPB.

2 ILOS 2013 yang dibangun menggunakan arsitektur prosesor 64-bit dan 32-bit.

3 Distro induk yang digunakan adalah distro Ubuntu 12.04.2 LTS.

4 Lingkungan desktop yang digunakan dalam penelitian ini adalah Unity yang merupakan lingkungan desktop default distro Ubuntu.

5 Aplikasi yang dipaketkan adalah aplikasi padanan yang dikembangkan dan didistribusikan dengan lisensi GNU GPL atau aplikasi propietary yang disebarkan sebagai freeware.

\section{METODE}

Penelitian ini dilakukan dalam beberapa tahapan, yaitu survei kebutuhan perangkat lunak di IPB studi pustaka, perumusan masalah, perancangan sistem, pengembangan sistem, dan pengujian.

\section{Survei Kebutuhan Perangkat Lunak di IPB}

Survei ini dilakukan di lingkungan kampus Dramaga, Institut Pertanian Bogor. Kegiatan survei dilakukan selama 6 (enam) minggu, yaitu pada minggu ke-3 Maret hingga minggu ke-4 
bulan April 2013. Pemetaaan kebutuhan perangkat lunak di IPB dilakukan dengan melakukan survei terhadap mahasiswa IPB. Teknik penarikan contoh yang digunakan dalam survei kebutuhan perangkat lunak ini adalah teknik penarikan contoh kuota (quota sampling).

Survei kebutuhan perangkat lunak dilakukan dalam 5 tahap yang dijelaskan oleh Connaway dan Powell (2010) sebagai tahapan dasar dalam penelitian survei, yaitu:

Merumuskan Tujuan. Memilih metode dan merancang teknik-teknik dalam setiap penelitian yang disesuaikan dengan tujuan yang didasarkan pada masalah yang akan diteliti. Dalam merumuskan tujuan perlu mencermati metode yang tepat untuk memastikan bahwa data yang dikumpulkan akan relevan dengan pertanyaan atau masalah yang diteliti.

Memilih Teknik Pengumpulan Data. Pengumpulan data dalam penelitian ini dilakukan dengan menyebarkan kuesioner. Pernyataan-pernyataan yang diajukan dalam kuesioner mempergunakan skala Likert. Menurut Azwar (2007), skala Likert digunakan untuk mengukur sikap, pendapat, dan persepsi sosial seseorang atau sekelompok orang tentang fenomena sosial. Skala Likert menghasilkan data yang berskala ordinal, yang menunjukkan perbedaan tingkatan subjek secara kuantitatif, dan dinyatakan dalam bentuk peringkat/rangking.

Erwindho (2011) menyatakan pilihan jawaban dalam skala Likert dapat terdiri atas 3 pilihan, 5 pilihan atau lebih banyak lagi. Sementara menurut Djaali (2008), skala Likert merupakan metode skala bipolar yang mengukur baik tanggapan positif ataupun negatif terhadap suatu pernyataan. Empat skala pilihan juga kadang digunakan untuk kuesioner skala Likert yang memaksa orang memilih salah satu kutub karena pilihan "netral" tak tersedia. Penelitian ini menggunakan skala Likert dengan 4 pilihan (Tabel 1).

Memilih Sampel. Sampel merupakan responden atau individu yang terpilih sebagai sampel penelitian. Menurut Nazir (2005), sampel adalah kumpulan dari unit sampling. Dalam memilih sampel, jumlah unit (sampel) penelitian terlebih dahulu ditentukan dengan rumus yang digunakan oleh Taro Yamane (1967) di dalam Akdon (2008), yaitu:

$$
n=\frac{N}{N \cdot d^{2}+1}
$$

n: Jumlah sampel; N: Jumlah total populasi; d: Presisi yang ditetapkan; 1: angka konstan

\section{Mengumpulkan Data.}

Setelah memilih koleksi data alat yang tepat dan sampel yang akan diterapkan, langkah berikutnya adalah mengumpulkan data dengan metode penarikan contoh kuota.

Menganalisis dan Menafsirkan Hasil. Proses analisis data yang dikumpulkan pada dasarnya melibatkan coding tanggapan, atau menempatkan setiap item dalam kategori yang sesuai, tabulasi data, dan melakukan perhitungan statistik yang sesuai. Akhir dari tahap ini peneliti harus menafsirkan dan menyimpulkan hasil survei berdasarkan hasil analisis dan pengolahan data yang dilakukan. Data diolah dengan menghitung rata-rata bobot setiap jawaban dengan menggunakan rumus:

$$
\mu=\frac{\sum\left(f_{i} \cdot b_{i}\right)}{N}
$$

$\mu$ : bobot rata-rata yang dicari; $f_{i}$ : frekuensi pilihan ke- $i ; b_{i}$ : bobot pilihan ke- $I ; N$ : total responden

Tabel 1 Pilihan jawaban kuesioner dan pembobotan

\begin{tabular}{lc}
\hline Pilihan & Bobot Pilihan \\
\hline Sangat Penting (SP) & 3 \\
Penting (P) & 2 \\
Kurang Penting (KP) & 1 \\
Tidak Penting (TP) & 0 \\
\hline
\end{tabular}




\section{Perumusan Masalah}

Perumusan masalah membahas bagaimana analisis kebutuhan dan permasalahan dalam pengembangan ILOS 2013 dilakukan. Meliputi batasan sistem, cara membuat distro Linux dengan teknik remastering, dan teknik pemilihan paket aplikasi.

\section{Perancangan Sistem}

Perancangan ILOS 2013 yang meliputi perancangan atribut, perancangan artwork, perancangan paket-paket aplikasi yang akan ditambahkan, dan perancangan modifikasi sistem dilakukan.

\section{Implementasi}

Tahap implementasi terdiri atas beberapa tahap, yaitu:

Pemilihan distribusi induk

Distribusi induk yang akan digunakan adalah Ubuntu 12.04.2 LTS (Precise Pangolin).

Penambahan dan penghapusan paket

Pada langkah ini dilakukan penghapusan paket yang tidak diperlukan pada distribusi induk dan penambahan paket aplikasi yang telah ditentukan berdasarkan survei kebutuhan perangkat lunak di IPB akan ditambahkan. Pada tahap ini juga akan dilakukan pemutakhiran sistem operasi.

Penyesuaian atribut distribusi induk

Pada tahap ini dilakukan pengubahan atribut sistem operasi untuk membedakan antara distribusi induk dan distribusi turunan. Atribut yang akan dilakukan penyesuaian adalah logo distribusi, wallpaper, bootscreen, loginscreen, dan identitas distribusi.

\section{Remastering}

Remastering merupakan tahap akhir implementasi sistem. Kegiatan pada tahap ini adalah pembuatan installer ILOS 2013 dalam bentuk DVD image berekstensi *.iso.

\section{Pengujian}

Pengujian dilakukan terhadap sistem operasi pada beberapa perangkat komputer dengan spesifikasi berbeda. Pengujian bertujuan untuk memeriksa dukungan distribusi ILOS 2013 terhadap perangkat keras komputer uji coba. Perangkat keras yang diujikan antara lain LAN card, kartu grafis, perangkat wireless, sound card, USB controller, dan bluetooth. Pengujian juga dilakukan untuk memastikan apakah aplikasi yang dipaketkan ke dalam distribusi ILOS 2013 berfungsi dengan baik.

\section{HASIL DAN PEMBAHASAN}

\section{Survei Kebutuhan Perangkat Lunak di IPB}

Menurut Singarimbun dan Effendi (1995), yang dimaksud dengan presisi adalah tingkatan ketepatan yang ditentukan oleh perbedaan hasil yang diperoleh dari sampel dibanding hasil yang diperoleh dari catatan lengkap, dengan syarat bahwa keadaan-keadaan dimana saat metode dilakukan, seperti daftar pertanyaan, teknik wawancara, kualitas pemecah, dan sebagainya, adalah sama atau disebut juga kesalahan baku.

Penelitian sosial biasanya menggunakan presisi yang berkisar antara 5\% sampai dengan $10 \%$ dan pada penelitian ini, penulis mengambil presisi sebesar $10 \%$ sehingga diperoleh jumlah sampel sebanyak:

$$
\mathrm{n}=\frac{26.927}{26.927 \times 0,1^{2}+1}=99,629 \approx 100
$$

Setelah jumlah sampel keseluruhan 100 orang diketahui,langkah selanjutnya ialah mengalokasikan atau menyebarkan satuan-satuan penarikan contoh ke setiap kelas atau 
klasifikasi yang telah ditetapkan. Pangalokasian sampel dilakukan secara proposional dengan menggunakan rumus yang dikemukakan oleh Sugiyono (1999), yaitu:

$$
s_{i}=\frac{n_{i}}{N} \times S
$$

$s_{i}$ : ukuran sampel yang harus diambil pada kelas ke- $i ; N=$ jumlah populasi; $n_{i}$ : ukuran populasi pada kelas ke- $i$; $S:$ jumlah sampel

Kuota sampel penarikan contoh untuk penentuan aplikasi pada distro ILOS 2013 dapat dilihat pada Tabel 2.

Pengolahan data dilakukan dengan melakukan perhitungan rata-rata bobot setiap pilihan jawaban berdasarkan bidang/rumpun ilmu responden. Bidang ilmu yang terdapat di IPB dikelompokkan ke dalam 4 kelompok bidang ilmu, yaitu: bidang sains (MIPA), agricultural (ilmu tumbuhan dan ilmu hewan), teknik, serta ekonomi dan sosial humaniora. Proses akhir pengolahan dan analisis data yaitu mengambil rata-rata bobot tertinggi setiap aplikasi dari semua kelompok bidang ilmu dan mengelompokkan setiap skor bobot tertinggi tersebut sesuai kriteria pada Tabel 3.

Tabel 2 Jumlah sampel berdasarkan klasifikasi program pendidikan

\begin{tabular}{lrc}
\hline Klasifikasi & Populasi (N) & Sampel (S) \\
\hline Diploma & 6671 & 25 \\
Sarjana & 16299 & 60 \\
Pascasarjana & 3957 & 15 \\
\hline Total & 26927 & 100 \\
\hline
\end{tabular}

Tabel 3 Daftar penafsiran bobot skor

\begin{tabular}{ll}
\hline Rentang Skor & Penafsiran \\
\hline $2.25-3.00$ & Aplikasi Prioritas \\
$1.50-2.24$ & Aplikasi Utama \\
$0.75-1.49$ & Aplikasi Penunjang \\
$0.00-0.74$ & Tidak Dipaketkan \\
\hline
\end{tabular}

Berdasarkan hasil pengolahan data survei, 5 aplikasi scientific, 7 aplikasi perkantoran, 5 aplikasi pemograman, 3 aplikasi basis data, 2 aplikasi jaringan, 1 aplikasi GIS, 5 aplikasi CAD dan desain grafis, 6 aplikasi internet, 3 aplikasi multimedia dan 1 aplikasi utilitas telah dipaketkan pada distro ILOS 2013. Daftar lengkap 38 aplikasi yang dipaketkan dapat dilihat pada Tabel 4.

\section{Pemilihan Distribusi Induk}

ILOS 2013 menggunakan distribusi Ubuntu 12.04.2 LTS sebagai distribusi induk. Pemilihan ini didasarkan pada beberapa hal, yaitu Ubuntu merupakan salah satu distribusi Linux yang paling mudah untuk digunakan bagi pemula Linux yang ingin beralih dari sistem operasi lain, Ubuntu memiliki komunitas pengguna yang sangat besar dan aktif dalam memberikan dukungan serta bantuan untuk penggunaan distribusinya, Ubuntu memiliki rilis long term support (LTS) yang mendapat dukungan secara resmi dari pengembang Ubuntu selama 5 tahun. Langkah awal pembuatan distribusi ILOS 2013 yaitu dengan melakukan instalasi Ubuntu 12.04.2 LTS pada notebook dengan spesifikasi hardware sebagai berikut: prosesor AMD A6-3400M 1.4GHz, RAM 6 GB DDR3, dan harddisk 750 GB.

\section{Penambahan dan Penghapusan Paket}

Sebelum dilakukan penambahan paket aplikasi, dilakukan penghapusan paket yang tidak dibutuhkan. Setelah aplikasi yang tidak dibutuhkan selesai dihapus, berikutnya dilakukan pemutakhiran sistem dengan menggunakan perintah: 
Tabel 4 Daftar aplikasi padanan yang dipaketkan ke dalam ILOS 2013

\begin{tabular}{|c|c|c|c|}
\hline No & Deskripsi & Perangkat lunak & $\begin{array}{l}\text { Padanan Aplikasi } \\
\text { GNU/Linux }\end{array}$ \\
\hline \multicolumn{4}{|c|}{ Perkantoran } \\
\hline & Program pengolah kata & Microsoft Word & Kingsoft Office Writer \\
\hline & Program untuk presentasi & Microsoft PowerPoint & Kingsoft Office Presentation \\
\hline & Program pengolah data dalam tabel & Microsoft Excel & $\begin{array}{l}\text { Kingsoft Office } \\
\text { Spreadsheets }\end{array}$ \\
\hline & Pembuka file PDF & Adobe PDF Reader & Document Viewer* \\
\hline & Pengolah kata sederhana & Notepad & Gedit* \\
\hline & PDF Editor & Adobe Acrobat & Master PDF Editor \\
\hline & Program pengolah diagram & Microsoft Visio & Dia \\
\hline \multicolumn{4}{|c|}{ Internet } \\
\hline & Web browser & Mozilla Firefox & Mozilla Firefox* \\
\hline & Web browser & Google Chrome & Chromium \\
\hline & Program pengirim pesan instan (chatting) & Yahoo Messenger & Pidgin \\
\hline & Plugin konten multimedia di web browser & Adobe Flash Player & Adobe Flash Player \\
\hline & Web browser & Internet Explorer & Chromium \\
\hline & Program komunikasi $\mathrm{P} 2 \mathrm{P}$ (peer to peer). & Skype & Skype \\
\hline & Program email client & Microsoft Outlook & Thunderbird* \\
\hline \multicolumn{4}{|c|}{ Scientific } \\
\hline & Program pengolah struktur kimia & ChemDraw & XdrawChem \\
\hline & Program pengolah data dan analisis statistik & SPSS & PSPP \\
\hline & Program pengolah data dan analisis statistik & Minitab & RKWard (R) \\
\hline & Program komputasi numerik & MATLAB & Freemat \\
\hline & $\begin{array}{l}\text { Program komputasi sains, teknik, dan } \\
\text { matematika }\end{array}$ & Mathematica & SAGEmath \\
\hline \multicolumn{4}{|c|}{ Pemograman } \\
\hline & Program pengolah vektor dan animasi & Adobe Flash & F4L \\
\hline & $\begin{array}{l}\text { IDE pemrograman } \mathrm{C}, \mathrm{C}++ \text { dan komputer } \\
\text { grafik }\end{array}$ & Dev C++ (+glut $)$ & Code::Blocks (+glut) \\
\hline & IDE pemrograman web & Dreamweaver & Bluefish \\
\hline & Prolog compiler & GNU Prolog & GNU Prolog \\
\hline & $\begin{array}{l}\text { IDE pemograman Java, PHP, C/C++, } \\
\text { HTML5 }\end{array}$ & Netbeans & Netbeans \\
\hline \multicolumn{4}{|c|}{ Basisdata } \\
\hline & Relational database management system & MySQL & MySQL \\
\hline & Database management system & Microsoft Access & LibreOffice Base \\
\hline & Algoritma machine learning data mining & Weka & Weka \\
\hline \multicolumn{4}{|c|}{ SIG } \\
\hline & $\begin{array}{l}\text { Program pengolah peta dan informasi } \\
\text { geografis }\end{array}$ & ArcGIS & Quantum GIS \\
\hline \multicolumn{4}{|c|}{ Jaringan Komputer } \\
\hline & Cisco router simulator & Packet tracer & Packet tracer \\
\hline & Program virtualisasi & VirtualBox & VirtualBox \\
\hline \multicolumn{4}{|c|}{ CAD dan Desain Grafis } \\
\hline & Program pengolah citra vektor & CorelDraw & Inkscape \\
\hline & Program pengolah citra raster (bitmap) & Adobe Photoshop & Gimp \\
\hline & CAD untuk menggambar teknik 2D \& 3D & AutoCAD & DraftSight \\
\hline & Aplikasi penyunting foto digital & Picassa & Picassa** \\
\hline & Program grafik vektor 3-dimensi dan animasi & 3D Studio Max & Blender \\
\hline \multicolumn{4}{|c|}{ Multimedia } \\
\hline & Audio dan video media player & Win. Media Player & SMPlayer \\
\hline & Audio dan video media player & Winamp & Clementine \\
\hline & Media player untuk media DVD & PowerDVD & SMPlayer \\
\hline & Aplikasi pemberi efek suara & Audacity & Audacity \\
\hline \multicolumn{4}{|c|}{ Utilitas } \\
\hline & Program pembuat dan pengolah cakram optik & Nero Burning Rom & Brasero* \\
\hline
\end{tabular}

\footnotetext{
*Terpasang secara default pada Ubuntu 12.04.2 LTS

** Dipasang melalui Wine
} 
sudo apt-get update

sudo apt-get upgrade

Tahap berikutnya adalah penambahan aplikasi yang akan dipaketkan ke dalam distribusi ILOS 2013, daftar aplikasi dapat dilihat pada Tabel 4. Penambahan paket dilakukan dengan 3 cara, yaitu: melalui Ubuntu Software Center untuk aplikasi yang telah tersedia pada repository Ubuntu, mengeksekusi perintah sudo apt-get install [nama paket] untuk aplikasi yang ditambahkan melalui repository PPA, mengeksekusi perintah sudo dpkg -i [nama paket] untuk aplikasi yang telah tersedia file berekstensi .deb.

\section{Penyesuaian Atribut Distribusi Induk}

Pengubahan atribut distribusi induk dilakukan untuk membedakan distribusi awal dengan distribusi Linux baru yang dikembangkan. Perubahan atribut tersebut meliputi perubahan Logo ILOS (Gambar 1), wallpaper (Gambar 2).

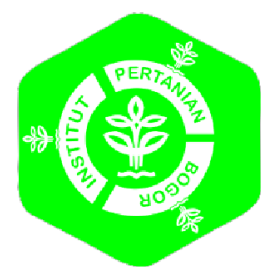

Gambar 1 Logo ILOS

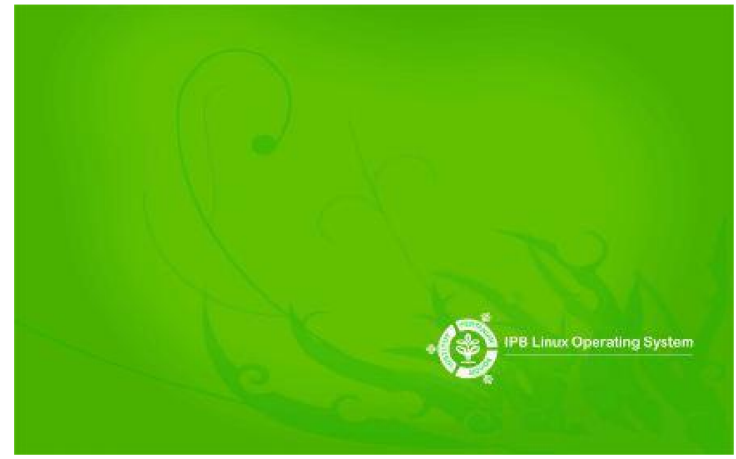

Gambar 2 Wallpaper ILOS 2013

Wallpaper yang telah dibuat dimasukkan ke direktori /usr/share/backgrounds, kemudian dilakukan pengubahan isi berkas-berkas berikut:

/usr/share/gnome-background-properties/ubuntu-wallpapers.xml

/usr/share/gconf/defaults/16_ubuntu-wallpapers.

Tema yang telah dibuat dan dimodifikasi dimasukkan ke direktori /usr/share/themes

\section{Bootscreen}

Pengubahan bootscreen dilakukan dengan mengubah gambar ubuntu-logo.png pada direktori /ib/plymouth dengan logo ILOS, mengubah berkas ubuntu-logo.grub dan ubuntulogo.scipt pada direktori /lib/plymouth/themes/ubuntu-logo/ untuk mengubah warna latar bootscreen, mengubah Ubuntu 12.04 LTS menjadi Ilos 2013 pada berkas ubuntutext.plymouth di dalam direktori /lib/plymouth/themes/ubuntu-text, dan melakukan update bootscreen dengan perintah sudo update-initramfs $-u$

\section{Identitas distribusi}

Terdapat beberapa berkas yang diubah pada tahap ini. Berkas pertama ialah /etc/lsbrelease yang berisi id distribusi, rilis, codename, dan deskripsi dari distribusi. Isi berkas sebelum diubah ialah sebagai berikut:

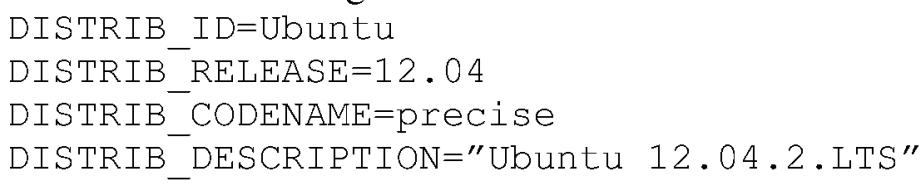


Isi berkas setelah berubah ialah sebagai berikut:

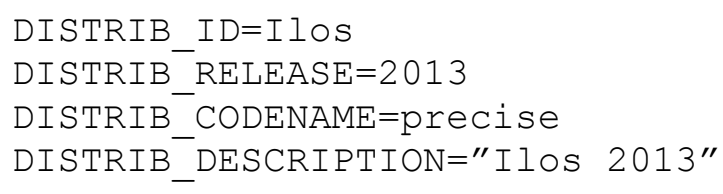

Atribut DISTRIB_DESCRIPTION tidak dilakukan pengubahan karena codename tersebut merupakan identitas untuk pengambilan paket aplikasi dari repository Ubuntu Precise Pangolin. Berkas kedua yang diubah ialah /etc/issue dengan perubahan pada bagian "Ubuntu 12.04 In VI" menjadi "Ilos 2013 In Vl". Berkas ketiga ialah /etc/issue.net dengan perubahan pada bagian Ubuntu 12.04 menjadi Ilos 2013.

Perubahan lain yang dilakukan ialah pembuatan berkas Ilos.py dengan menyalin dan mengubah nama Ubuntu.py pada direktori /usr/share/software-center/distro, kemudian mengubah setiap kata Ubuntu (ubuntu dengan U kapital) pada berkas Ilos.py menjadi Ilos, serta pembuatan berkas Ilos.info dan Ilos.mirror pada direktori /usr/share/pyhtonapt/templates/ dengan menyalin dan mengubah nama Ubuntu.info dan Ubuntu.mirror

\section{Remastering}

Tahap akhir pengembangan distribusi ILOS 2013 adalah melakukan remastering dengan menggunakan tool Remastersys. Sebelum proses remastering dilakukan, ada beberapa berkas dan direktori yang harus disalin ke direktori /etc/skel/, berkas dan direktori tersebut adalah .conf, .gconf, .gnome2, /Document, /Download, /Music, /Picture, dan /Video.

Selanjutnya, isi direktori temporary dihapus untuk meminimalkan ukuran berkas iso yang akan menjadi installer distribusi ILOS 2013. Penghapusan berkas pada direktori temporary tersebut dilakukan dengan menjalankan perintah sudo $\mathrm{rm}-\mathrm{rf} / \mathrm{tmp} / *$. Setelah itu lakukan remastering dengan menjalankan perintah sudo remastersys dist. Hasil remastering terdapat pada direktori /home/remastersys.

\section{Pengujian}

Pada tahap ini dilakukan pengujian terhadap distribusi ILOS 2013. Pengujian dilakukan terhadap perangkat keras pada mesin komputer yang berbeda. Pada distribusi ILOS 2013 lima komputer (destop dan notebook) yang diujicobakan secara live CD (langsung dijalankan melalui CD) dan Instalasi (ILOS 2013 diinstal pada harddisk) dapat berjalan dengan baik. Adapun proses detail pengujian perangkat keras berupa LAN card, dilakukan koneksi internet pada komputer uji; kartu grafis, dilakukan perubahan resolusi monitor pada komputer uji; perangkat wireless, dilakukan koneksi ke jaringan wireless pada komputer uji; sound card, menjalankan berkas suara dengan aplikasi Clementine; USB controller, dilakukan pemindahan data dengan media flashdisk serta menjalankan mouse pada komputer uji; dan bluetooth, dilakukan pemindahan data dengan media ponsel.

\section{SIMPULAN}

Penelitian ini menghasilkan sebuah sistem operasi turunan Ubuntu 12.04.2. LTS yang diberi nama ILOS 2013. Aplikasi yang dipaketkan pada ILOS 2013 ditetapkan berdasarkan hasil survei dengan metode penarikan contoh kuota terhadap 100 orang mahasiswa IPB. Pada ILOS 2013, telah dipaketkan sebanyak 38 aplikasi untuk mendukung kebutuhan mahasiswa IPB.

\section{DAFTAR PUSTAKA}

Akdon. 2008. Aplikasi Statistika. Bandung (ID): Alfabeta.

Ardhie SP. 2011. Pengembangan distribusi ILOS for Computer Science (ILOS CS) [skripsi]. Bogor (ID): Institut Pertanian Bogor. 
Azwar S. 2007. Reliabilitas dan validitas. Yogyakarta (ID): Pustaka Pelajar.

Connaway LS, Powell RR. 2010. Basic research methods for Librarians. Ed ke-5. California (US): ABC-CLIO.

Djaali H. 2008. Psikologi pendidikan. Jakarta (ID): Bumi Aksara.

Erwindho K. 2011. Pengaruh kompetensi tim penyusun anggaran terhadap efektivitas pengendalian anggaran di lingkungan Kanwil Kementerian Agama Provinsi DKI Jakarta [tesis]. Bandar Lampung (ID): Universitas Lampung.

Feri M. 2011. Pengembangan distribusi IPB Linux Open Source for Business (ILOSbiz) [skripsi]. Bogor (ID): Institut Pertanian Bogor.

Lubis IA. 2008. Konsep dasar pembuatan distribusi ILOS hasil turunan distribusi PCLinuxOS [skripsi]. Bogor (ID): Institut Pertanian Bogor.

Manunggal A. 2009. Pengembangan distribusi ILOS for Education (ILOSEDU) [skripsi]. Bogor (ID): Institut Pertanian Bogor.

Musthofa. 2011. Pengembangan distribusi ILOS Multimedia (ILOSmedia) [skripsi]. Bogor (ID): Institut Pertanian Bogor.

Nazir M. 2005. Metode Penelitian. Bogor (ID): Ghalia Indonesia

Sugiyono. 2004. Statistika untuk Penelitian. Bandung (ID): Alfabeta

Singarimbun M, Effendi S. 1995. MetodePpenelitian Survei. Jakarta (ID): Pustaka LP3ES

Yamane T. 1967. Elementary SamplingTheory. Englewood Cliffs (US): Prentice-Hall. 